\title{
Preparation and Corrosion Resistance of Micro-arc oxidation Coated Biomedical Mg-Zn-Ca Alloy in the Silicon-Phosphorus Mixed Electrolyte
}

\author{
Yansong Wang ${ }^{\dagger}$, Minfang Chen ${ }^{\dagger}, \tilde{\hbar}, \xi *$, Yun Zhao ${ }^{\dagger, t, \xi}$
}

$\uparrow$ School of Materials Science and Engineering, Tianjin University of Technology, Tianjin 300384,

China

†Tianjin Key Lab for photoelectric Materials \& Devices, Tianjin 300384, China

$\S$ Key Laboratory of Display Materials and Photoelectric Device (Ministry of Education), Tianjin

$$
\text { 300384, China }
$$

Corresponding Author Prof. Minfang Chen

*E-mail: mfchentj@163.com. FAX: +0086-22-60215845 (M.-F.C.). 


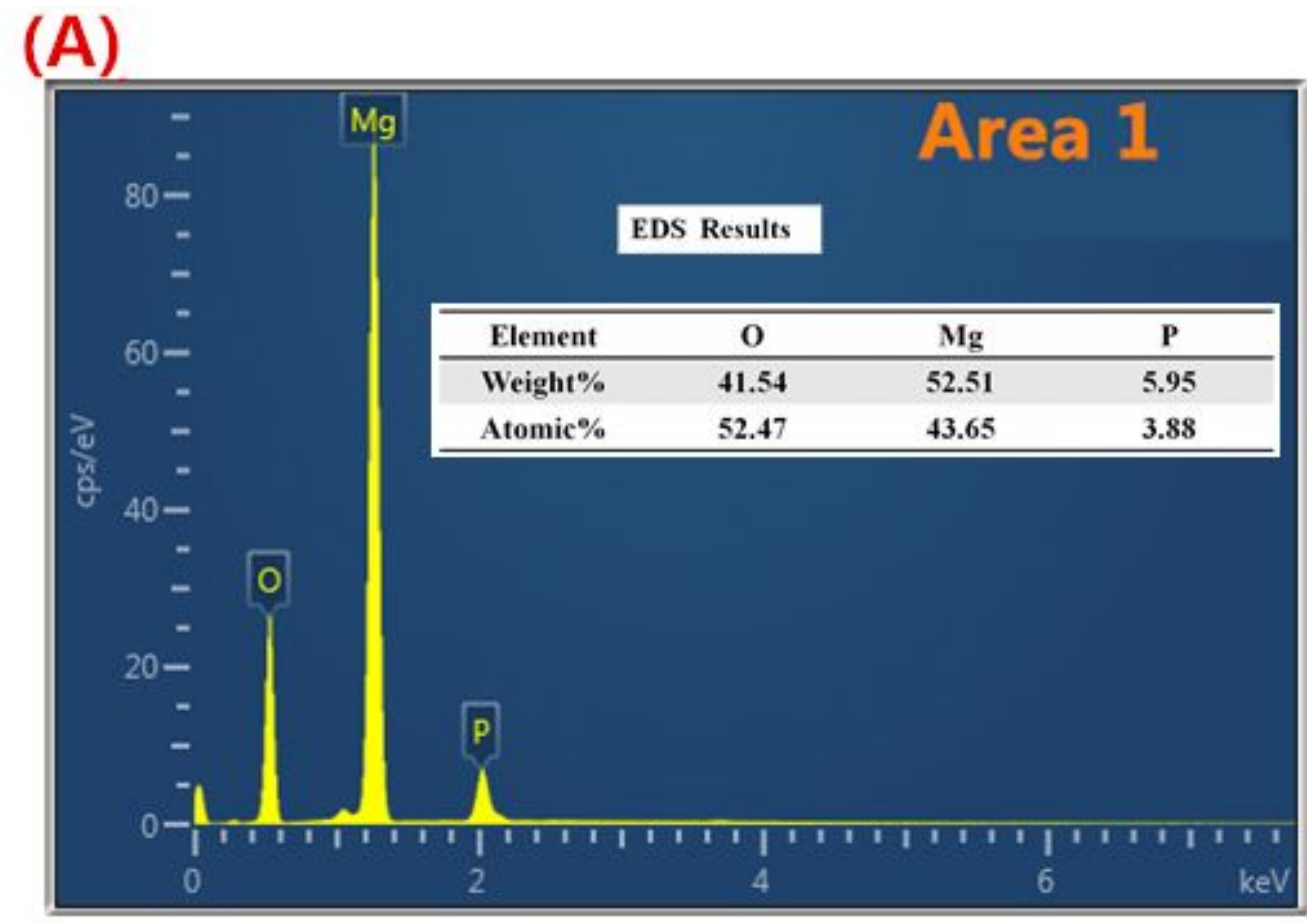

(B)

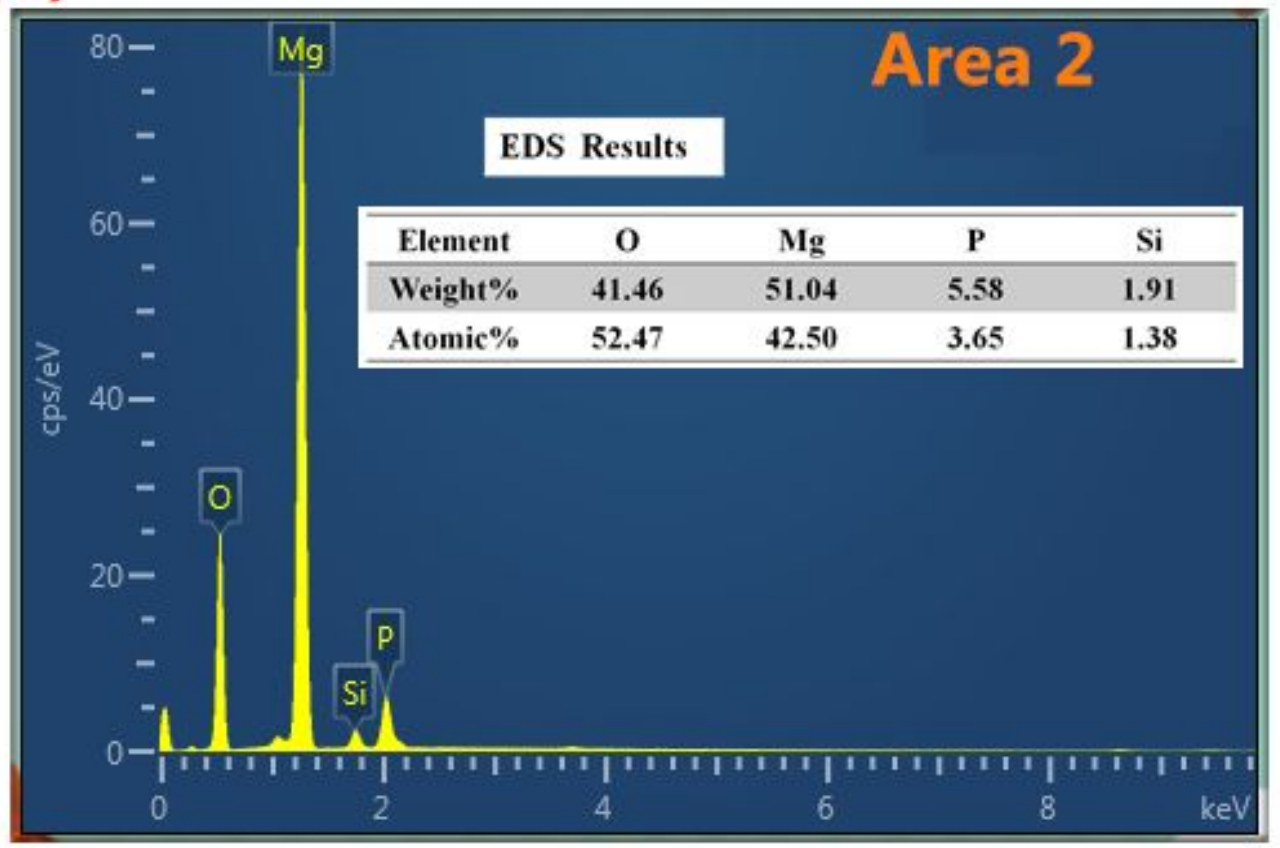


(C)

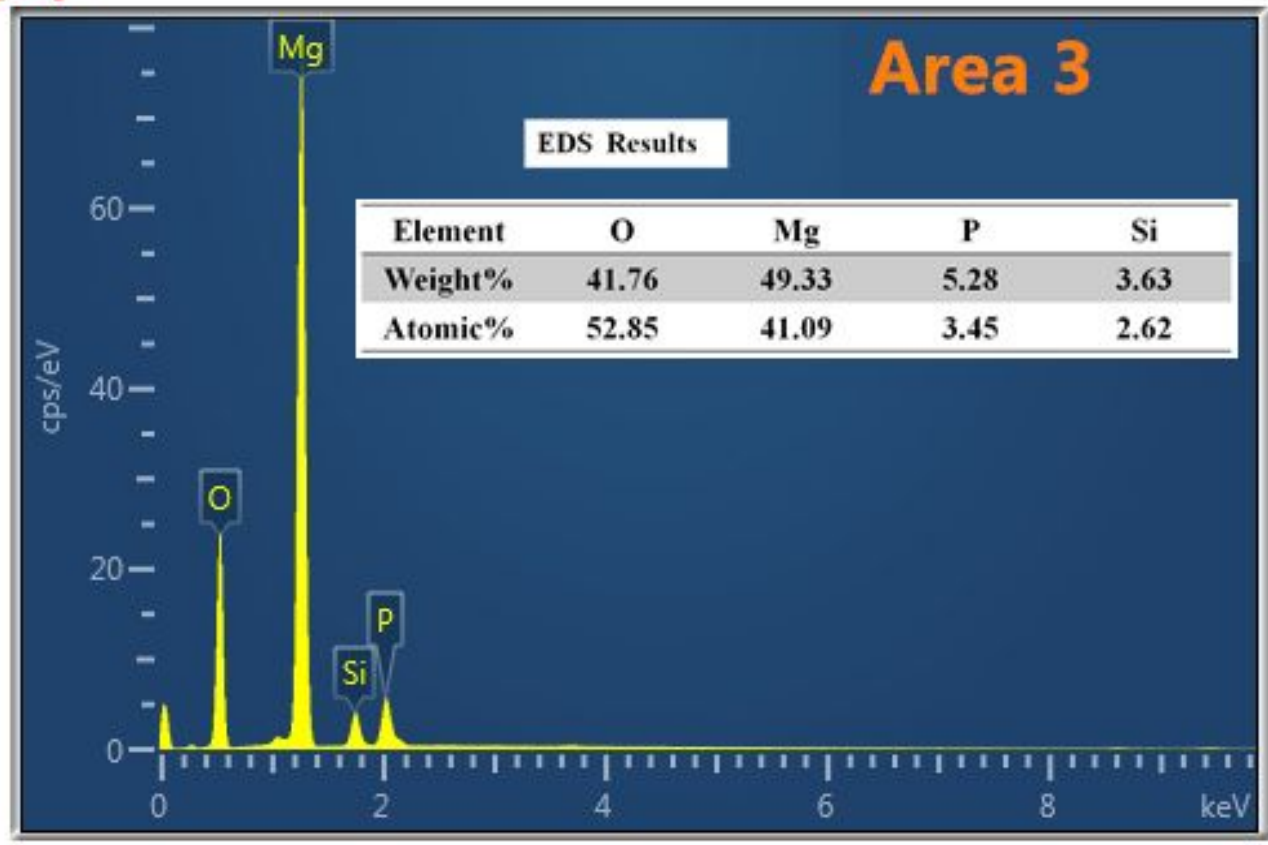

(D)

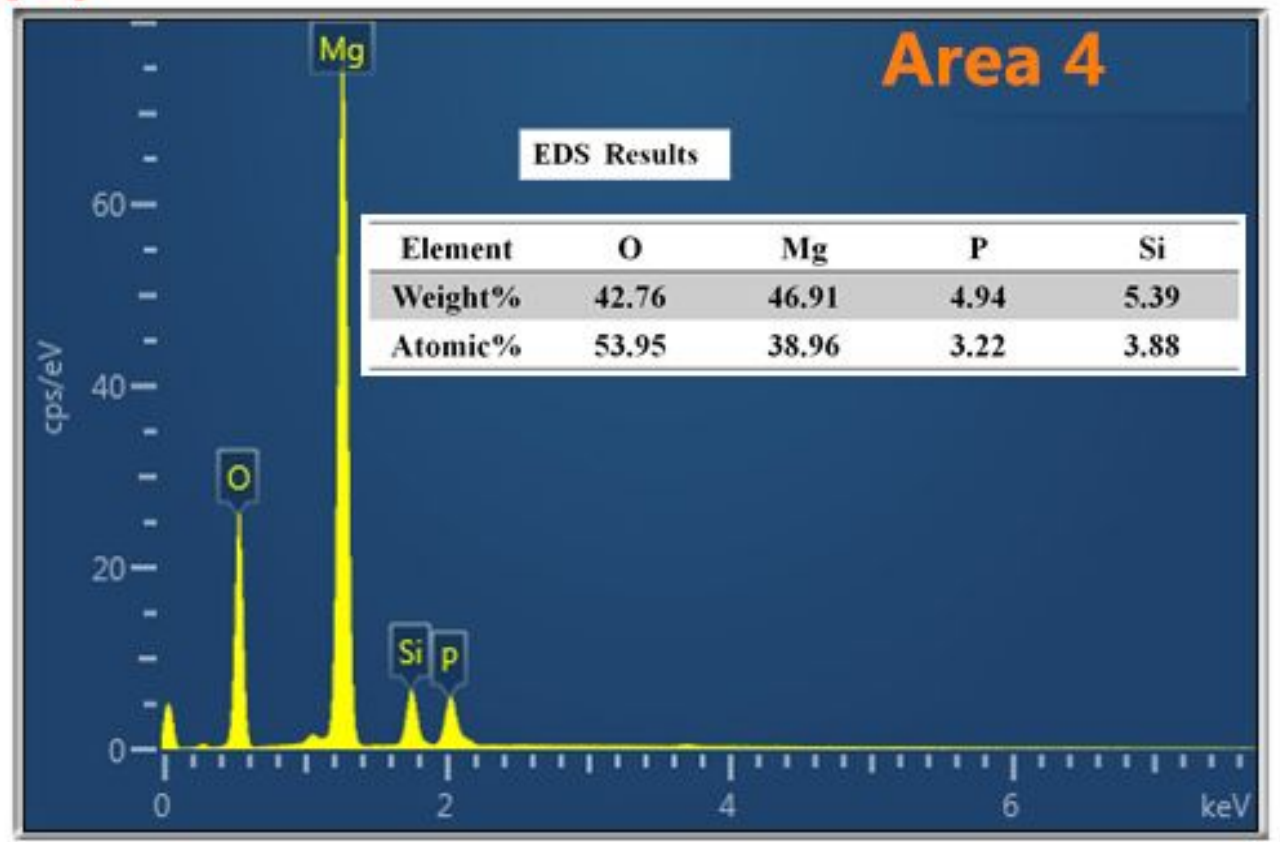




\section{(E)}

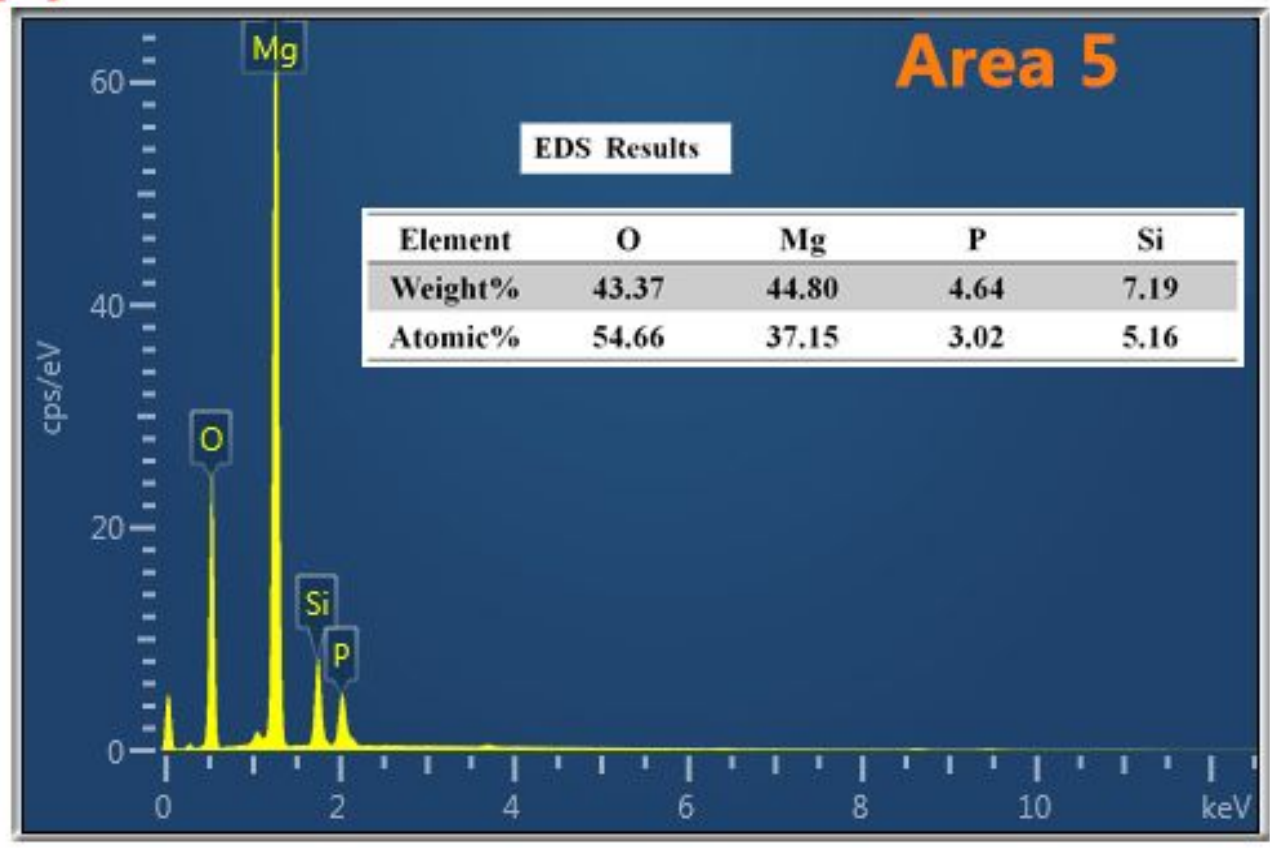

Figure S1. EDS element analysis of M1 M5 coated samples (A-E) 


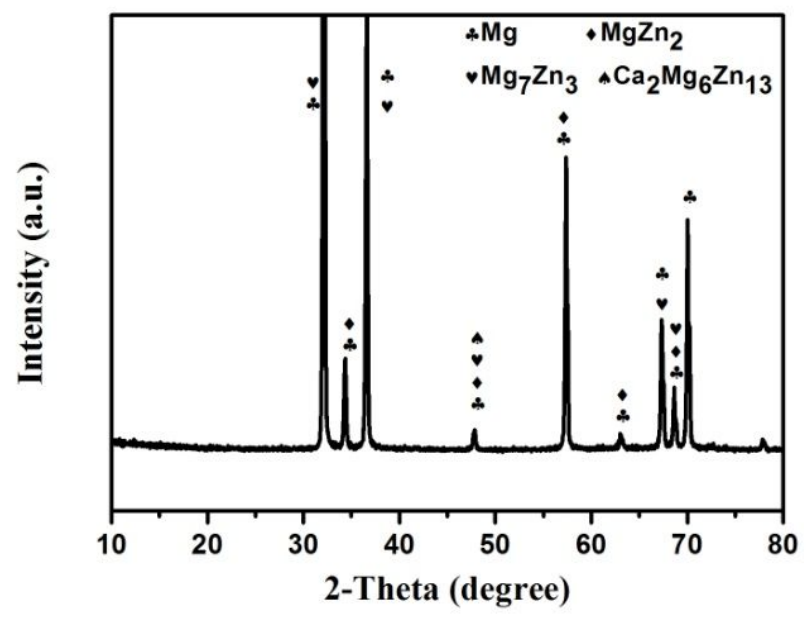

Figure S2. The XRD pattern of uncoated substrate samples. 
(A)

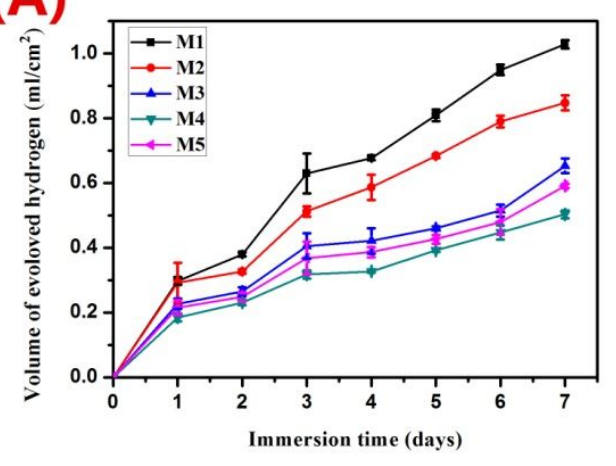

(B)

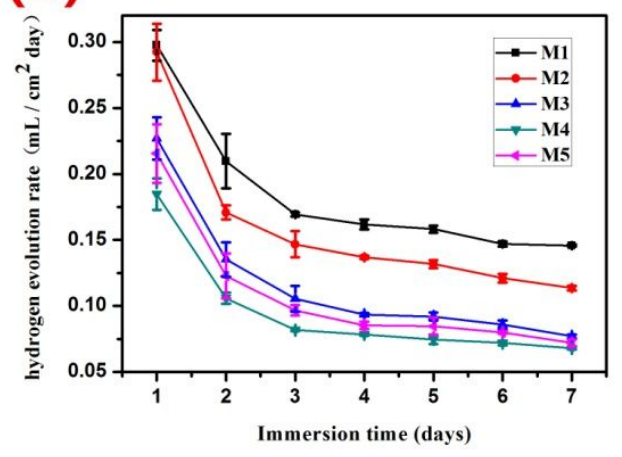

Figure S3. Volume of evoloved hydrogen (A) and hydrogen evolution rate (B) of M1-M5 coated samples after immersion in $\mathrm{SBF}($ mean $\pm \mathrm{SD}, n=3$ ).

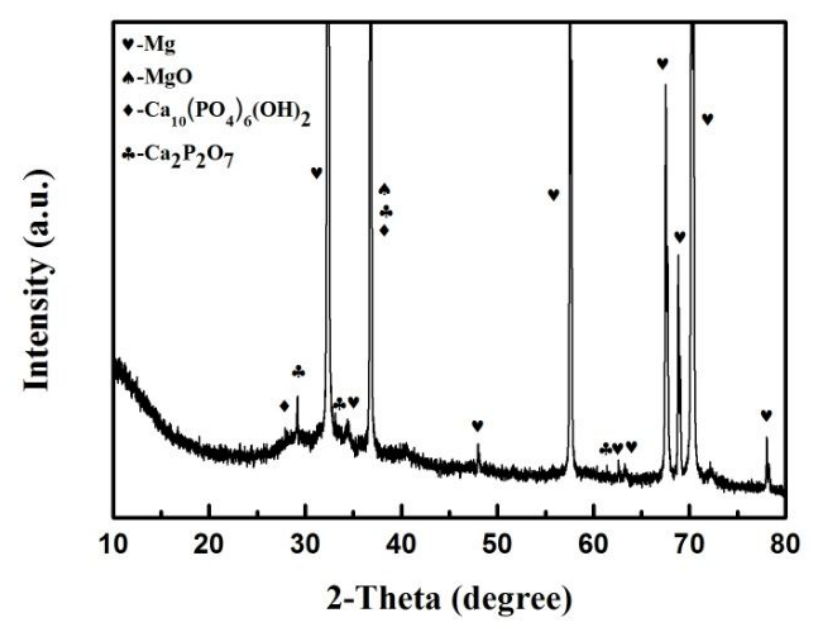

Figure S4. The XRD patterns of the M4 coated sample immersed in SBF for $168 \mathrm{~h}$. 


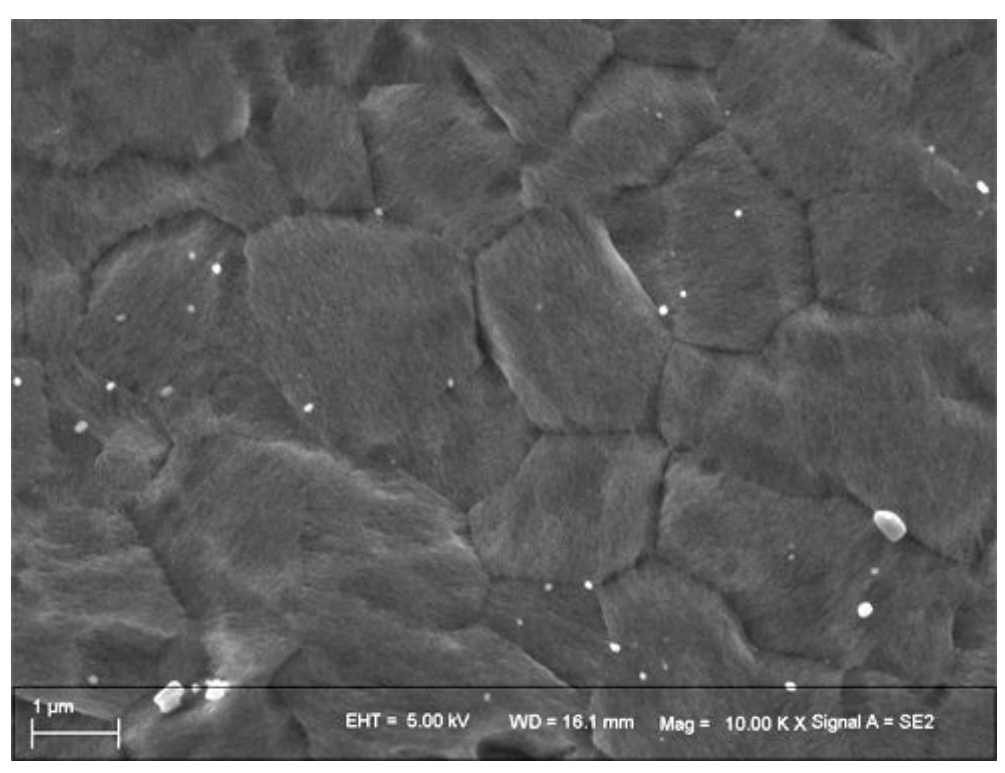

Figure S5. Metallograph of the Mg-3Zn-0.2Ca alloy. 